\title{
BRPKM
}

Buletin Riset Psikologi dan Kesehatan Mental

http://e-journal.unair.ac.id/index.php/BRPKM

e-ISSN: 2776-1851

ARTIKEL PENELITIAN

\section{Pemetaan Faktor Determinan Perilaku Masturbasi Berlebihan pada Individu Dewasa Awal}

\author{
RHAJIV NUR ILHAM \& AFIF KURNIAWAN* \\ Fakultas Psikologi Universitas Airlangga
}

\begin{abstract}
ABSTRAK
Masturbasi merupakan perilaku seksual yang umum tetapi bersifat kompulsif. Masturbasi yang tidak dikendalikan dengan baik dapat mengarah pada masturbasi berlebihan. Penelitian ini bertujuan untuk memetakan faktor determinan perilaku masturbasi berlebihan pada individu dewasa awal. Penelitian ini melibatkan 268 partisipan (183 laki-laki dan 85 perempuan) yang berusia 18-40 tahun. Data dalam penelitian ini dianalisis dengan menggunakan uji regresi linear berganda dan uji independent sample ttest. Hasil analisis menunjukkan bahwa terdapat perbedaan skor rata-rata masturbasi berlebihan yang signifikan antara laki-laki dan perempuan $(0,000<0,05)$. Prevalensi masturbasi berlebihan pada lakilaki lebih tinggi daripada perempuan. Selain itu, Kontrol diri $(\beta=-0,178 ; p<0,01)$, konsumsi pornografi problematis $(\beta=0,387 ; p<0,01)$, dan sikap terhadap masturbasi $(\beta=-0,032 ; p<0,05)$ berpengaruh signifikan terhadap masturbasi berlebihan, sedangkan tingkat stress $(\beta=0,069 ; p>0,05)$ dan kebosanan dalam waktu luang $(\beta=0,011 ; p>0,05)$ tidak berpengaruh signifikan terhadap masturbasi berlebihan.
\end{abstract}

Kata kunci: kontrol diri, masturbasi berlebihan, pornografi, sikap, stress

\section{ABSTRACT}

Masturbation is a common yet compulsive sexual behavior. Masturbation that is not managed well can lead to excessive masturbation. This study aims to map determinant factors of excessive masturbation among early adults. This study involved 268 participants (183 males and 85 females) who aged around 18-40 years old. Data in this study was analyzed using multiple regression analysis and independent sample t-test. Result shows that there is significant mean difference of excessive masturbation score between males and females $(0,000<0,05)$. The prevalence of excessive masturbation in males is higher than that in females. Moreover, self-control $(\beta=-0,178 ; p<0,01)$, problematic pornography consumption $(\beta=0,387 ; p<0,01)$, and attitude toward masturbation $(\beta=-0,032 ; p<0,05)$ have significant effect on excessive masturbation. However, level of stress $(\beta=0,069 ; p>0,05)$ and leisure boredom $(\beta=0,011$; $p>0,05$ ) have insignificant effect on excessive masturbation.

Keywords: attitude, excessive masturbation, pornography, self-control, stress

Buletin Penelitian Psikologi dan Kesehatan Mental (BRPKM), 2021, Vol. 1(1), 734-745

*Alamat korespondensi: Fakultas Psikologi Universitas Airlangga, Kampus B Universitas Airlangga Jalan Airlangga 4-6 Surabaya 60286. Surel: afif.kurniawan@psikologi.unair.ac.id

Naskah ini merupakan naskah dengan akses terbuka dibawah ketentuan the Creative Common Attribution License (CC-BY-4.0) (http://creativecommons.org/licenses/by/4.0), 
sehingga penggunaan, distribusi, reproduksi dalam media apapun atas artikel ini tidak dibatasi, selama sumber aslinya disitir dengan baik.

\section{PE N D A H U L U A N}

Masa dewasa awal merupakan masa dimana individu berusaha untuk menyesuaikan diri dengan polapola kehidupan yang baru (Hurlock, 2000). Oleh karena itu individu dewasa awal cenderung bersikap eksploratif, namun tidak stabil pada masa-masa transisi dari remaja menuju dewasa (Arnett, 2017). Masa dewasa awal juga dikenal sebagai masa reproduktif bagi individu (Hurlock, 2000). Organ kelamin individu pada masa tersebut telah berkembang secara matang sehingga aktivitas seksualnya juga turut berkembang (Hurlock, 2000; Dariyo, 2003. Franzfabian dan Dewi (2015) menjelaskan bahwa masa dewasa awal merupakan masa dimana individu menentukan sikap terhadap aktivitas seksualnya. Erikson (dalam Hurlock, 2000) menjelaskan bahwa pada masa tersebut masyarakat menuntut agar individu segera menikah, namun pada kenyataannya ada banyak individu dewasa yang memutuskan untuk menunda pernikahan atau bahkan tidak menikah sama sekali karena berbagai alasan (Jayanti \& Masykur, 2015). Dariyo (2003) menjelaskan bahwa individu yang tidak menikah akan mengalami kesulitan dalam menyalurkan dorongan seksualnya sehingga harus menemukan cara alternatif untuk menyalurkan hasrat seksual. Salah satu cara yang dapat dilakukan untuk menyalurkan hasrat seksual adalah dengan melakukan masturbasi (Kaestle \& Allen, 2011). Masturbasi dianggap sebagai pilihan terbaik untuk menyalurkan dorongan seksual ketika individu belum memiliki ikatan perkawinan yang sah, takut dengan risiko penularan penyakit seksual, dan menghindari kehamilan yang tidak diinginkan (Kaestle \& Allen, 2011).

Masturbasi merupakan salah satu aktivitas seksual yang ditujukan untuk memenuhi hasrat seksual dan memuaskan diri sendiri dengan merangsang alat kelamin sendiri dengan tangan (Tukan, 1993). Astawauliyah (dalam Parasantya, 2019) menjelaskan bahwa masturbasi dapat dilakukan oleh siapa saja, baik laki-laki ataupun perempuan. Meskipun praktiknya berbeda antara laki-laki dan perempuan, namun tujuan masturbasi adalah untuk menyalurkan hasrat seksual yang tidak dapat disalurkan (Kontula \& Haavio-Mannila, 2003). Ahsin dan Hafidz (2007) mengklasifikasikan masturbasi ke dalam dua jenis, yaitu masturbasi aktif dan masturbasi pasif. Mastursbasi aktif merupakan perilaku masturbasi yang dilakukan dengan tangan ataupun benda lain oleh diri sendiri, sedangkan masturbasi pasif adalah perilaku masturbasi yang dilakukan dengan bantuan orang lain (Ahsin \& Hafidz, 2007). Pada dasarnya kemunculan perilaku masturbasi merupakan fenomena yang normal, tetapi perlu diwaspadai karena masturbasi merupakan perilaku seksual kompulsif (Abramson \& Mosher, 1975). Masturbasi yang tidak dikendalikan dengan baik akan mengarahkan individu pada perilaku masturbasi berlebihan (excessive masturbation). Karia, dkk. (2015) menjelaskan bahwa masturbasi berlebihan merupakan salah satu tipe kelainan parafilia dimana individu terlibat dalam perilaku masturbasi yang melampaui batas dan menyebabkan disfungsi sosial.

Badan Kesehatan Dunia (WHO) mengklasifikasikan perilaku masturbasi berlebihan sebagai gangguan emosional dan perilaku. Masturbasi berlebihan terjadi ketika individu tidak mampu menahan dorongan seksual dalam dirinya dan kehilangan kontrol atas perilaku masturbasi yang dilakukan sehingga masturbasi terjadi secara kompulsif (Cuncic, 2020). Masturbasi berlebihan memiliki dampak negatif yang besar terhadap produktivitas individu dalam kehidupan sehari-hari (Shekarey, dkk., 2011); Cuncic, 2020). Masturbasi berisiko menimbulkan kelelahan yang besar secara fisik dan psikologis sehingga akan menghambat individu dalam menyelesaikan tugas sehari-hari (Shekarey, dkk., 2011). Abramson (1973) menjelaskan bahwa laki-laki yang bermasturbasi dengan intensitas tinggi memiliki risiko

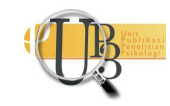


mengalami gangguan neurotik yang lebih besar daripada mereka yang bermasturbasi dengan intensitas lebih rendah dan mereka yang bermasturbasi dengan intensitas tinggi juga menunjukkan kecenderungan menarik diri dari lingkungan sosial. Masturbasi berlebihan pada laki-laki juga dapat meningkatkan risiko individu mengalami pembengkokan organ kelamin (Peyronie's disease) (India Times, 2018). Rizaldi (2014) mengemukakan bahwa individu yang bermasturbasi lebih dari dua kali seminggu memiliki risiko lebih besar untuk memperoleh indeks prestasi belajar kurang dari 3,50 daripada mereka yang bermasturbasi kurang dari dua kali seminggu. Selain itu, masturbasi yang berlebihan berisiko menyebabkan ketidakpuasan dengan pasangan ketika melakukan penetrasi karena berkurangnya sensitivitas organ kelamin (India Times, 2018; Cuncic, 2020). Lebih lanjut, masturbasi berlebihan dapat memberikan efek yang fatal, bahkan menyebabkan kematian. Parasantya (2019) menyebutkan bahwa setidaknya terdapat 80 hingga 100 kasus kematian akibat perilaku masturbasi berisiko di Jerman. Harald Voss (dalam Parasantya, 2019) menjelaskan bahwa alasan paling umum dari kematian akibat masturbasi adalah karena ingin mencapai orgasme yang maksimal namun kekurangan oksigen. Parasantya (2019) juga menyebutkan bahwa seorang laki-laki di Afrika Selatan dilaporkan tewas setelah melakukan masturbasi sebanyak 62 kali berturut-turut di hari kasih sayang akibat mengalami depresi.

Seiring dengan berjalannya waktu, perilaku masturbasi menjadi semakin tidak asing. Meskipun demikian, pembahsan terkait perilaku masturbasi dianggap sangat tabu (Bockting, 2002), termasuk dalam masyarakat Indonesia. Perilaku masturbasi dianggap sebagai perilaku yang bertentangan dengan norma agama, seperti dalam ajaran Islam, Kristen, dan Yahudi (Gerressu, dkk., 2008) sehingga masyarakat enggan untuk membahas perilaku tersebut dalam ruang-ruang publik. Sulzer-Azarof dan Mayer (1977) mengungkapkan bahwa agar dapat mengendalikan atau mengubah suatu perilaku maka individu perlu memahami faktor-faktor apa saja yang menyebabkan kemunculan perilaku tersebut. Berkaitan dengan hal tersebut, sulit untuk memahami perilaku masturbasi ketika ruang diskusi yang tersedia sangat terbatas. Hal tersebut menjadi salah satu dorongan penulis untuk meneliti perilaku masturbasi berlebihan di Indonesia.

Masturbasi pada dasarnya muncul karena berbagai faktor, seperti kurangnya kemampuan dalam menjaga pandangan, kurangnya kemampuan dalam mengelola pikiran-pikiran sensual, kurangnya kegiatan positif, kurangnya edukasi seksual, dan adanya pengaruh media pornografi (Ngadiyo, 2010). Warlenda, dkk. (2018) mengungkapkan bahwa perilaku masturbasi muncul karena adanya pengaruh media massa, kurangnya pengetahuan tentang masturbasi, kurangnya peran orang tua, dan adanya pengaruh teman sebaya. Sharafi (2000) menjelaskan bahwa masturbasi dapat muncul karena adanya pengaruh dari banyak faktor, antara lain adanya rasa penasaran, perasaan tidak familiar dengan isu seksual, perasaan diasingkan, permasalahan keluarga, permasalahan dengan teman sebaya, perasaan inferior, adanya imitasi, pubertas dini, sensitivitas kulit kelamin, stres, adanya konflik masa kecil, dan kurangnya afeksi. Debs (1956, dalam Shekarey, dkk., 2011) mengungkapkan bahwa individu bermasturbasi karena mengalami perasaan diasingkan dan kesepian.

Sharafi (2000) mengungkapkan bahwa masturbasi dipengaruhi oleh latar belakang budaya, sehingga sebab-sebab terjadinya masturbasi mungkin akan bervariasi, tergantung dimana mereka tinggal. Oleh karena itu, penulis melakukan studi pendahuluan untuk melihat sejauh mana permasalahan tentang masturbasi terjadi di Indonesia dan apa saja faktor determinan yang umum dalam memunculkan perilaku masturbasi. Berdasarkan studi pendahuluan yang melibatkan 159 partisipan, sebanyak 88\% laki-laki dan 36\% perempuan pernah melakukan masturbasi. Lebih lanjut, sebanyak 51\% laki-laki dan $24 \%$ perempuan melakukan masturbasi setidaknya tiga kali dalam seminggu. Sejalan dengan itu, Kasemy, dkk. (2016) mengungkapkan bahwa prevalensi masturbasi pada laki-laki lebih tinggi daripada perempuan. Bahkan studi di Amerika Serikat menunjukkan bahwa 70\% laki-laki tetap bermasturbasi 
meskipun mereka merasa bersalah karena melakukannya (Sine, 2013). Berdasarkan alasan kemunculannya, sebanyak 37\% partisipan mengungkapkan bahwa mereka bermasturbasi karena tidak mampu mengendalikan dorongan seksual, 24\% partisipan melakukan masturbasi karena menikmati konten-konten pornografi, 23\% partisipan melakukan masturbasi karena mengalami stres, dan 8\% partisipan merasa bahwa masturbasi merupakan kebutuhan yang tidak dapat ditinggalkan. Selain menggunakan kuesioner, penulis juga mengumpulkan data studi pendahuluan menggunakan teknik wawancara. Berdasarkan wawancara dengan dengan dua partisipan, perasaan bosan selama waktu luang menjadi salah satu alasan mereka melakukan masturbasi. Iso-Ahola dan Weissinger (1987) mengungkapkan bahwa semakin individu mempersepsikan waktu luang sebagai situasi yang membosankan, maka semaki besar risiko individu tersebut terlibat dalam perilaku kenakalan remaja ataupun perilaku lain yang tidak dibenarkan.

Berdasarkan penelitian yang sudah ada sebelumnya, perilaku masturbasi muncul ketika individu gagal dalam mengontrol dorongan seksual dalam dirinya (Siswanto \& Rezda, 2014; Noor, 2015). Kontrol diri berperan dalam mengendalikan perilaku tersebut. Messina dan Messina (2003) menjelaskan bahwa kontrol diri merupakan aspek psikologis dalam diri individu yang berperan dalam menentukan keberhasilan individu dalam mengendalikan perilakunya, menolak pengerusakan diri, dan memisahkan emosi dengan rasionalitas (Kenyawati, 2018). Selain kurangnya kontrol diri, individu yang mengalami stres juga berisiko melakukan masturbasi. Malfetti dan Eidlitz (1973) mengemukakan bahwa masturbasi digunakan sebagai alternatif untuk melepaskan perasaan cemas dan tertekan sehingga individu yang mengalami stres banyak yang bermasturbasi. Ngadyo (2010) menjelaskan bahwa masturbasi dapat pula terjadi karena adanya pengaruh media pornografi. Perilaku konsumsi pornografi menunjukkan korelasi positif yang signifikan dengan intensitas melakukan masturbasi (Lichyati, 2009; Siswanto \& Rezda, 2014). Pada dasarnya, perilaku muncul karena adanya sikap yang mendasarinya, termasuk dalam perilaku masturbasi. Abdullah (2014) mengungkapkan bahwa sikap terhadap masturbasi berkorelasi signifikan terhadap kemunculan perilaku masturbasi. Eliyanti, dkk. (2012) yang melakukan penelitian di Kecamatan Indralaya Utara, Sumatera Selatan juga mengungkapkan bahwa semakin negatif sikap individu terhadap masturbasi, maka semakin kecil intensitas individu tersebut bermasturbasi.

Berdasarkan paparan permasalahan dan studi terdahulu, maka penulis memutuskan melakukan penelitian untuk memetakan faktor determinan perilaku masturbasi berlebihan di Indonesia. Hal tersebut dimaksudkan agar individu dapat memahami lebih dalam terkait kemunculan perilaku masturbasi berlebihan.

Hipotesis $\mathrm{Nul}\left(\mathrm{H}_{0}\right)$ dalam penelitian ini adalah:

1. Tidak terdapat pengaruh yang signifikan antara kontrol diri terhadap perilaku masturbasi berlebihan.

2. Tidak terdapat pengaruh yang signifikan antara tingkat stres terhadap perilaku masturbasi berlebihan.

3. Tidak terdapat pengaruh yang signifikan antara konsumsi pornografi problematis terhadap perilaku masturbasi berlebihan.

4. Tidak terdapat pengaruh yang signifikan antara kebosanan dalam waktu luang terhadap perilaku masturbasi berlebihan.

5. Tidak terdapat pengaruh yang signifikan antara sikap terhadap masturbasi terhadap perilaku masturbasi berlebihan.

6. Tidak terdapat perbedaan nilai rata-rata perilaku masturbasi berlebihan antara laki-laki dan perempuan. 
Hipotesis Kerja (Ha) dalam penelitian ini adalah:

1. Terdapat pengaruh yang signifikan antara kontrol diri terhadap perilaku masturbasi berlebihan.

2. Terdapat pengaruh yang signifikan antara tingkat stres terhadap perilaku masturbasi berlebihan

3. Terdapat pengaruh yang signifikan antara konsumsi pornografi problematis terhadap perilaku masturbasi berlebihan.

4. Terdapat pengaruh yang signifikan antara kebosanan dalam waktu luang terhadap perilaku masturbasi berlebihan.

5. Terdapat pengaruh yang signifikan antara sikap terhadap masturbasi terhadap perilaku masturbasi berlebihan.

6. Terdapat perbedaan nilai rata-rata perilaku masturbasi berlebihan antara laki-laki dan perempuan.

\section{Desain Penelitian}

\section{E T O D E}

Penelitian ini menggunakan pendekatan kuantitatif eksplanatori. Pendekatan tersebut bertujuan untuk menggambarkan sebuah permasalahan dan menjelaskan hubungan antar variabel sehingga dapat mengetahui sebab-sebab terjadinya suatu permaslahan. Metode pengumpulan data yang digunakan dalam penelitian ini adalah metode survei dengan media berupa skala kuesioner. Metode survei dipilih karena memiliki keunggulan dalam mengukur variabel dengan jumlah yang banyak sekaligus (Neuman, 2007). Berdasarkan dimensi waktu, penelitian ini termasuk dalam kategori cross-sectional.

\section{Partisipan}

Partisipan dalam penelitian ini merupakan individu dewasa awal di Indonesia yang melakukan masturbasi setidaknya tiga kali dalam seminggu dan memiliki keyakinan subjektif bahwa masturbasi adalah hal yang penting dalam hidup. Penelitian ini menggunakan teknik random sampling untuk mengumpulkan partisipan penelitian. Teknik tersebut digunakan untuk memberikan peluang yang sama kepada seluruh anggota populasi agar dapat menjadi partisipan penelitian (Sugiyono, 2010). Partisipan dalam penelitian ini diharuskan mengisi informed consent sebelum mengisi kuesioner penelitian.

Penelitian ini melibatkan 268 partisipan $\left(M_{u s i a}=21,43 ; S D_{u s i a}=2,12 ; 68,3\right.$ persen laki-laki; 31,7 persen perempuan). Partisipan dalam penelitian ini berusia 18-40 tahun dan didominasi oleh kelompok usia 18-25 tahun (95,5\%). Sebagian besar pasrtisipan dalam penelitian ini memiliki latar belakang pendidikan terakhir sarjana $(67,5 \%)$.

\section{Pengukuran}

Penelitian ini terdiri dari enam variabel bebas dan satu variabel terikat. Variabel bebas dalam penelitian ini antara lain kontrol diri, tingkat stres, konsumsi pornografi problematis, kebosanan dalam waktu luang, sikap terhadap masturbasi, dan perbedaan jenis kelamin. Variabel terikat dalam penelitian ini adalah perilaku masturbasi berlebihan. Variabel kontrol diri diukur dengan menggunakan skala Brief Self Control Scale (BSCS) yang dikembangkan oleh Tangney, dkk. (2004) dan terdiri dari 13 aitem. Setiap aitem dalam skala BSCS disusun menggunakan skala likert dengan rentang respon 1 sampai 5 (1="sangat tidak sesuai dengan diri saya", 5="sangat sesuai dengan diri saya"). Variabel tingkat stres diukur dengan menggunakan skala Perceived Stress Scale (PSS-10) yang dikembangkan oleh Cohen dan Williamson (1988) dan terdiri dari 10 aitem. Setiap aitem dalam skala PSS-10 disusun menggunakan 
skala likert dengan rentang respon 0 sampai 4 (0="tidak pernah", 4="selalu"). Variabel konsumsi pornografi problematis diukur dengan menggunakan skala Problematic Pornography Consumption Scale (PPCS-6) yang dikembangkan oleh Bőthe, dkk. (2020) dan terdiri dari 6 aitem. Setiap aitem dalam skala PPCS-6 disusun menggunakan skala likert dengan rentang respon 1 sampai 7 (1="tidak pernah", $7=$ "selalu"). Variabel kebosanan dalam waktu luang diukur dengan menggunakan skala Leisure Boredom Scale (LBS) yang dikembangkan oleh Iso-Ahola dan Wissinger (1990) dan terdiri dari 16 aitem. Setiap aitem dalam skala LBS disusun menggunakan skala likert dengan rentang respon 1 sampai 5 (1="sangat tidak setuju", 5="sangat setuju"). Variabel sikap terhadap masturbasi diukur dengan menggunakan skala Negative Attitude toward Masturbation Inventory (NAMI) yang dikembangkan oleh Abramson dan Mosher (1975) dan terdiri dari 30 aitem. Setiap aitem dalam skala NAMI disusun menggunakan skala likert dengan rentang respon 1 sampai 5 (1="sangat setuju", 5="sangat tidak setuju"). Variabel perbedaan jenis kelamin diidentifikasi menggunakan instrumen sosiodemografis (1="laki-laki, $2=$ "perempuan"). Variabel perilaku masturbasi berlebihan diukur dengan menggunakan skala BergenYale Sex Addiction Scale (BYSAS) yang dikembangkan oleh Andreasen, dkk. (2018) dan terdiri dari 6 aitem. Setiap aitem dalam skala BYSAS disusun menggunakan skala likert dengan rentang respon 0 sampai 4 (0="tidak pernah", 4="sangat sering").

Alat ukur dalam penelitian ini telah diuji validitasnya menggunakan teknik professional judgement dengan melibatkan ahli. Selain uji validitas, alat ukur dalam penelitian ini juga telah diuji reliabilitasnya. Reliabilitas semua skala diukur diuji dengan menggunakan teknik Cronbach's Alpha dan masing-masing menunjukkan derajat reliabilitas yang baik. Skala BSCS memiliki nilai Cronbach's Alpha sebesar .80, skala PSS-10 memiliki nilai Cronbach's Alpha sebesar .71, skala PPCS-6 memiliki nilai Cronbach's Alpha sebesar .87, skala LBS memiliki nilai Cronbach's Alpha sebesar .84, skala NAMI memiliki nilai Cronbach's Alpha sebesar .90, dan skala BYSAS memiliki nilai Cronbach's Alpha sebesar .81. Menurut Ghozali (2015) skala yang memiliki derajat reliabilitas yang baik adalah skala dengan nilai Cronbach's Alpha > .70. Dengan demikian, semua skala yang digunakan dalam penelitian ini telah menunjukkan derajat reliabilitas yang baik.

Data dalam penelitian ini telah memenuhi uji asumsi klasik untuk analisis regresi. Uji asumsi meliputi uji normalitas, uji heteroskedastisitas, uji linearitas, dan uji multikolinearitas. Uji normalitas dilakukan dengan uji Kolmogorov-Smirnov dan diperoleh nilai signifikansi sebesar 0,2 yang artinya data berdistribusi normal. Uji heteroskedastisitas dilakukan dengan melihat sebaran data pada scatterplot. Berdasarkan scatterplot, data terlihat menyebar dan tidak membentuk pola tertentu sehingga dikatakan tidak menunjukkan gejala heteroskedastisitas. Uji linearitas dilakukan dengan melihat nilai deviasi linearitas. Jika nilai deviasi linearitas lebih dari 0,05 maka data dikatakan linear. Semua variabel bebas dalam penelitian ini menunjukkan nilai deviasi linearitas lebih dari 0,05 sehingga dapat dikatakan linear. Selanjutnya, uji multikolinearitas dilakukan dengan melihat nilai toleransi dan Variance Inflation Factor (VIF). Jika nilai toleransi $>0,1$ dan nilai VIF $<10$ maka dapat disimpulkan bahwa tidak terdapat masalah multikolinearitas. Semua variabel bebas dalam penelitian ini menunjukkan nilai toleransi $>0,1$ dan nilai VIF < 10 sehingga disimpulkan bahwa tidak terdapat masalah multikolinearitas.

\section{Analisis Data}

Teknik analisis yang digunakan dalam penelitian ini meliputi uji regresi linier berganda dan uji independent sample t-test. Uji regresi linier berganda dilakukan untuk mengetahui besaran dan signifikansi pengaruh variabel bebas terhadap variabel terikat secara simultan, sedangkan uji independent sample t-test dilakukan untuk mengetahui apakah terdapat perbedaan skor rata-rata 
perilaku masturbasi berlebihan yang signifikan antara laki-laki dan perempuan. Data dalam penelitian ini diolah dengan menggunakan perangkat lunak IBM SPSS version 25.00 for MacBook.

\section{HAS IL P ENELITIAN}

Hasil analisis deksriptif menunjukkan bahwa sebanyak 38 partisipan (14,2\%) memiliki kontrol diri yang rendah, 201 partisipan (75\%) memiliki kontrol diri yang sedang, dan 29 partisipan $(10,8 \%)$ memiliki kontrol diri yang tinggi. Berdasarkan tingkat stres, sebanyak 36 partisipan $(13,4 \%)$ mengalami stres ringan, 189 partisipan (70,5\%) mengalami stres sedang, dan 43 partisipan (16\%) mengalami stres berat. Berdasarkan derajat adiksi pornografi, sebanyak 87 partisipan (32,5\%) menunjukkan derajat adiksi yang rendah, 147 partisipan (54,9\%) menunjukkan derajat adiksi yang sedang, dan 34 partisipan $(12,7 \%)$ menunjukkan derajat adiksi yang tinggi. Berdasarkan tingkat kebosanan dalam waktu luang, sebanyak 34 partisipan (12,7\%) mengalami kebosanan dengan tingkat rendah, 201 partisipan (75\%) mengalami kebosanan dengan tingkat sedang, dan 33 partisipan (12,3\%) mengalami kebosanan dengan tingkat tinggi. Berdasarkan sikap partisipan terhadap masturbasi, sebanyak 136 partisipan (50,7\%) memiliki sikap positif terhadap masturbasi dan 132 partisipan $(49,3 \%)$ memiliki sikap negatif terhadap masturbasi. Berdasarkan perilaku masturbasi berlebihan, sebanyak 69 partisipan $(25,7 \%)$ mengalami adiksi masturbasi dengan derajat rendah, 142 partisipan (53\%) mengalami adiksi masturbasi dengan derajat sedang, dan 57 partisipan (21,3\%) mengalami adiksi masturbasi dengan derajat tinggi. Kategorisasi skor tersebut menggunakan norma dari Azwar (2011).

Hasil uji regresi linear berganda menunjukkan bahwa kontrol diri, tingkat stres, konsumsi pornografi problematis, kebosanan dalam waktu luang, dan sikap terhadap masturbasi secara simultan mampu menjelaskan variasi perilaku masturbasi berlebihan sebesar 50,7\% $(F(5,262)=53,884 ; p<0,05$; $\left.\mathrm{R}^{2}=0,507\right)$. Kontrol diri $(\beta=-0,178 ; 95 \%$ CI $[-0,271 ;-0,086] ; \mathrm{SE}=0,047 ; \mathrm{t}=-3,79 ; \mathrm{p}<0,01)$, konsumsi pornografi problematis $(\beta=0,387 ; 95 \%$ CI $[0,322 ; 0,452]$; $S E=0,033 ; t=11,72 ; p<0,01)$, dan sikap terhadap masturbasi $(\beta=-0,032 ; 95 \%$ CI $[-0,064 ;-0,001]$; $S E=0,016 ; t=-2,03 ; p<0,05)$ secara parsial memiliki pengaruh yang signifikan terhadap perilaku masturbasi berlebihan. Namun, tingkat stres $(\beta=0,069 ; 95 \%$ CI $[-0,023 ; 0,161] ; \mathrm{SE}=0,047 ; t=1,47 ; \mathrm{p}>0,05)$ dan kebosanan dalam waktu luang $(\beta=0,011 ; 95 \%$ CI $[-0,045 ; 0,068]$; $S E=0,029 ; t=0,39 ; p>0,05)$ secara parsial tidak memiliki pengaruh yang signifikan terhadap perilaku masturbasi berlebihan. Berdasarkan hasil uji regresi linear berganda, perilaku masturbasi berlebihan dapat ditampilkan dalam persamaan regresi dengan rumus $Y=9,055$ $0,178 X 1+0,069 X 2+0,387 X 3+0,011 X 4-0,032 X 5+e(X 1=$ kontrol diri; X2=tingkat stres; X3=konsumsi pornografi problematis; $\mathrm{X} 4=$ =kebosanan dalam waktu luang; $\mathrm{X} 5=$ sikap terhadap masturbasi; $Y=$ perilaku masturbasi berlebihan; e=pengaruh variabel lain yang tidak diteliti).

Hasil uji independent sample t-test menunjukkan bahwa terdapat perbedaan skor rata-rata perilaku masturbasi berlebihan antara laki-laki $(N=183 ; M=11,82 ; S D=4,95)$ dan perempuan $(N=85 ; M=9,38$; $S D=5,36)$. Perbedaan skor rata-rata perilaku masturbasi berlebihan pada laki-laki dan perempuan bernilai signifikan $(\mathrm{t}(266)=3,66 ; \mathrm{p}=0,000 ; 95 \%$ CI $[1,129 ; 3,757])$.

\section{I S K U S I}

Masturbasi berlebihan dalam International Statistical Classificationof Disease (ICD) diklasifikasikan sebagai salah satu bentuk gangguan emosi dan perilaku. Masturbasi umumnya dilakukan lebih sering oleh laki-laki daripada perempuan (Kasemy, dkk., 2016). Berdasarkan studi yang dilakukan oleh Roy Baumeister di Amerika Serikat, setidaknya 70\% laki-laki tetap melakukan masturbasi meskipun mereka mengalami perasaan bersalah karena melakukannya. Sine (2013) menjelaskan bahwa terdapat 
beberapa alasan fundamental mengapa laki-laki melakukan masturbasi dengan intensitas lebih tinggi daripada perempuan. Pada dasarnya, laki-laki dan perempuan memiliki perbedaan dalam pengelolaan dorongan seksual (Sine, 2013). Laki-laki lebih sering berpikir tentang hal-hal yang berhubungan tentang seks daripada perempuan dan secara biologis laki-laki lebih mudah menerima dan mengaktivasi rangsangan seksual daripada perempuan (Sine, 2013). Lebih lanjut Sine (2013) menjelaskan bahwa laki-laki memiliki keinginan lebih besar untuk terlibat dalam aktivitas seksual yang intensif daripada perempuan. Pusat Studi Stres Manusia (CSHS) di California membuktikan bahwa laki-laki memiliki kecendurungan untuk terlibat dalam aktivitas koping yang maladaptif daripada perempuan ketika menghadapi stres.

Baldwin dan Baldwin (2002, dalam Ramachandran, 2002) mengungkapkan bahwa pada dasarnya perilaku seksual, seperti masturbasi, muncul karena adanya interaksi antara kondisi neural dan hormonal dari dalam tubuh dengan faktor-faktor sosial dan kultural. Dalam kehidupan sosial, perempuan dilaporkan memiliki kontrol diri yang lebih baik daripada laki-laki (Feingold, 1994; Costa, dkk., 2001). Messina dan Messina (2003) mengungkapkan bahwa kontrol diri yang baik dalam diri individu akan membantu individu tersebut dalam mengendalikan perilaku dan menolak pengerusakan diri, termasuk hal-hal yang berlebihan seperti masturbasi berlebihan. Individu dengan kontrol diri yang rendah akan mengalami kesulitan untuk mengendalikan perilakunya meskipun mereka tahu bahwa perilaku tersebut akan menimbulkan dampak-dampak negatif bagi diri mereka (Kenyawati, 2018). Tangney, dkk. (2004) menjelaskan bahwa kontrol diri merupakan entitas psikologis yang multi-aspek. Lebih lanjut Tangney, dkk. (2004) menjelaskan bahwa individu dengan kontrol diri yang rendah akan cenderung terlibat dalam perilaku-perilaku yang impulsif, destruktif, dan tidak sehat, sebagimana masturbasi berlebihan dianggap sebagai perilaku yang destruktif dan tidak sehat (Abramson, 1973; Karia, dkk., 2015). Dalam penelitian-penelitian yang telah ada, kontrol diri yang rendah kerap dihubungkan dengan peningkatan perilaku seksual yang berisiko (Galliot \& Baumeister, 2007), seperti masturbasi berlebihan.

Masturbasi selama ini dianggap sebagai sebuah alternatif untuk melepaskan diri dari tekanan-tekanan yang dirasakan (Malfetti \& Eidlitz, 1973; Kurnia, 2016). Meskipun demikian, pada dasarnya masturbasi tidak dapat diimplementasi oleh semua orang sebagai salah satu bentuk koping stres. Stres sendiri merupakan persepsi individual tentang tegangan yang dialami oleh individu akibat adanya hal-hal tidak terduga, tidak terkontrol, dan melampaui batas kemampuannya (Cohen \& Williamson, 1988). Pusat Studi Stres Manusia (CSHS) di California menjelaskan bahwa perbedaan persepsi terhadap stres tersebut akan mempengaruhi individu dalam menentukan strategi koping sehingga masturbasi mungkin tidak selalu menjadi cara terbaik untuk meredakan stres. Pada dasarnya, strategi koping stres individu akan berbeda-beda, tergantung latar belakang budaya, pengalaman, lingkungan, dan bahkan kepribadian (Maryam, 2017).

Aktivitas seksual, seperti masturbasi, kerap kali dihubungkan dengan keterlibatan media pornografi. Ngadyo (2010) mengungkapkan bahwa kemunculan perilaku masturbasi disebabkan oleh adanya pengaruh media pornografi. Konsumsi pornografi memiliki hubungan yang kuat dengan intensitas perilaku masturbasi, artinya semakin konsumtif individu terhadap media pornografi maka semakin tinggi intensitas perilaku masturbasinya (Siswanto \& Rezda, 2014; Yutifa, dkk., 2015; Brito, 2019). Pornografi merupakan suatu bentuk stimulus seksual yang mampu meningkatkan dorongan seksual, tetapi berisiko menimbulkan emosi-emosi negatif (Laan \& Everaerd, 1995). Ketika dorongan seksual membuncah tetapi individu tidak dapat menyalurkannya maka akan menimbulkan perasaan tidak nyaman dan tidak tenang. Oleh karena itu, masturbasi dianggap sebagai alternatif yang paling aman untuk menyalurkan dorongan seksual, terutama bagi individu yang belum menikah (Kaestle \& Allen, 2011).

Buletin Riset Psikologi dan Kesehatan Mental (BRPKM) 2021, Vol. 1(1), 734-745 
Masturbasi dianggap sebagai suatu aktivitas yang dapat menghapus perasaan bosan selama waktu luang oleh sebagian individu. Kebosanan dalam waktu luang sendiri merupakan manifestasi dari adanya persepsi atas kebosanan dan kepuasan (Iso-Ahola \& Weissinger, 1987; Gurbuz, dkk., 2014). O'Hanlon (1981) menjelaskan bahwa kebosanan dalam waktu luang merupakan persepsi subjektif, sebagaimana persepsi atas kepuasan juga bersifat subjektif. Oleh karena itu, tidak semua individu akan mempersepsikan masturbasi sebagai suatu aktivitas yang dapat memberikan kepuasan selama waktu luang yang tersedia. Meskipun demikian, Schenk (2009) mengungkapkan bahwa kebosanan dalam waktu luang mampu memberikan $2,2 \%$ variasi pada perilaku konsumsi pornografi.

Green (1991) mengungkapkan bahwa suatu perilaku tertentu muncul karena adanya sikap yang mendasarinya, sebagaimana perilaku masturbasi berlebihan juga demikian. Sikap yang semakin positif terhadap perilaku masturbasi akan meningkatkan keterlibatan individu pada perilaku masturbasi (Eliyanti, dkk., 2012; Abdullah, 2014). Ray dan Afflerbach (2014) menemukan fakta bahwa individu yang saat kecil diajarkan tentang dampak-dampak negatif masturbasi dan diharuskan menghindari perilaku tersebut sehingga memiliki kepercayaan dan penilaian yang negatif terhadap masturbasi akan memiliki kecenderungan lebih besar untuk menjauhi perilaku masturbasi. Azwar (1995) menjelaskan bahwa sikap terdiri atas tiga aspek, yaitu aspek kognitif, afektif, dan perilaku. Individu yang memiliki persepsi dan emosi yang negatif terhadap perilaku masturbasi akan cenderung menghindari perilaku masturbasi tersebut karena menurut Azwar (2010) respon individual seperti pikiran dan perasaan akan menentukan cara individu tersebut berperilaku.

\section{S I M P U L A N}

Berdasarkan hasil penelitian, dapat disimpulkan bahwa secara simultan kontrol diri, tingkat stres, konsumsi pornografi problematis, kebosanan dalam waktu luang, dan sikap terhadap masturbasi memiliki pengaruh yang signifikan terhadap perilaku masturbasi berlebihan. Kontrol diri, konsumsi pornografi problematis, dan sikap terhadap masturbasi secara parsial memiliki pengaruh yang signifikan terhadap perilaku masturbasi berlebihan, sedangkan tingkat stres dan kebosanan dalam waktu luang secara parsial tidak memiliki pengaruh yang signifikan terhadap perilaku masturbasi berlebihan. Konsumsi pornografi problematis memberikan kontribusi paling besar dan signifikan terhadap kemunculan perilaku masturbasi berlebihan, diikuti dengan kontribusi dari variabel kontrol diri dan sikap terhadap masturbasi. Selain itu, terdapat perbedaan yang signifikan dari nilai rata-rata perilaku masturbasi berlebihan pada laki-laki dan perempuan. Prevalensi masturbasi berlebihan pada laki-laki menunjukkan angka yang lebih besar daripada perempuan.

Penelitian ini hanya meneliti sebagian faktor determinan perilaku masturbasi berlebihan, sehingga penelitian selanjutnya disarankan untuk meneliti pengaruh dari faktor determinan lainnya seperti jumlah waktu luang yang tersedia, pengawasan keluarga, peran orang tua, tingkat pengetahuan individu tentang masturbasi, perasaan inferior, perasaan kesepian, perasaan terisolasi, kurangnya afeksi, dan latar belakang keluarga (Sharafi, 2000; Shekarey, dkk., 2011). Hasil dari penelitian ini menunjukkan bahwa kontrol diri, konsumsi pornografi problematis, dan sikap terhadap masturbasi memiliki pengaruh yang signifikan terhadap perilaku masturbasi berlebihan sehingga penulis menyarankan individu untuk memperbanyak aktivitas olah pikir dan olah rasa seperti meditasi untuk melatih kontrol diri, berolahraga dan melakukan hobi yang bermanfaat untuk mengisi waktu luang sehingga tidak terlibat interaksi dengan media pornografi, serta mempelajari perilaku masturbasi secara lebih dalam, terutama efek-efek negatif yang ditimbulkan jika dilakukan secara berlebihan agar individu bersikap waspada. Selain itu, untuk masyarakat sebagai keluarga dapat menggunakan hasil penelitian untuk memahami perkembangan seksual anak dan mengantisipasi terjadinya masturbasi berlebihan pada anak.

Buletin Riset Psikologi dan Kesehatan Mental (BRPKM) 2021, Vol. 1(1), 734-745 


\section{U C A P A N T ER I MAKASIH}

Terima kasih kepada Tuhan Yang Maha Esa, seluruh partisipan penelitian yang berkenan berkontribusi dalam penelitian ini, dan seluruh pihak yang telah membantu proses penyelesaian rangkaian penelitian hingga hasil penelitian ini dapat dipublikasikan. Semoga penelitian ini dapat memberikan sumbangsih dalam kemajuan ilmu pengetahuan di bidang psikologi dan kesehatan mental.

\section{DEKLARASI POTENSI TERJADINYA KONFLIK KEPENTINGAN}

Rhajiv Nur Ilham dan Afif Kurniawan tidak bekerja, menjadi konsultan, memiliki saham, atau menerima dana dari perusahaan atau organisasi manapun yang mungkin akan mengambil untung dari diterbitkannya naskah ini.

\section{PUST AKA ACUAN}

Abdullah, A. (2014). Hubungan Pengetahuan dan Sikap Remaja Laki-Laki dengan Kejadian Masturbasi.

Abramson, P. R. (1973). The Relationship of the Frequency of Masturbation to Several Aspects of Personality and Behavior. In The Journal of Sex Research (Vol. 9, Issue 2).

Abramson, P. R., \& Mosher, D. L. (1975). Development of a Measure of Negative Attitudes Toward Masturbation. In Journal of Consulting and Clinical Psychology (Vol. 43, Issue 4).

Arnett, J. J. (2017). Adolescence and Emerging Adulthood. Pearson.

Bockting, W. O. (2002). Masturbation as a Means of Achieving Sexual Health. Journal of Psychology and Human Sexuality, 1-4.

Dariyo, A. (2003). Psikologi Perkembangan Dewasa Muda. Grasindo.

Dwi Jayanti, R., Mujab Masykur, A., \& Soedarto Tembalang Semarang, J. S. (2015). PENGAMBILAN KEPUTUSAN BELUM MENIKAH PADA DEWASA AWAL (Vol. 4, Issue 4).

Eliyanti, I., Alam Fajar, N., \& Fakultas Kesehatan Masyarakat Universitas Sriwijaya, A. (2012). FAKTOR YANG BERHUBUNGAN DENGAN PERILAKU MASTURBASI PADA REMAJA SMA DI KECAMATAN INDRALAYA UTARA TAHUN 2010.

Fauzan Franzfabian, A., \& Dewi, K. S. (2015). HIDUP DENGAN PERILAKU SEKS BEBAS PADA INDIVIDU DEWASA AWAL SEBUAH INTERPRETATIVE PHENOMENOLOGICAL ANALYSIS (Vol. 4, Issue 2).

Gerressu, M., Mercer, C. H., Graham, C. A., Wellings, K., \& Johnson, A. M. (2008). Prevalence of masturbation and associated factors in a British national probability survey. Archives of Sexual Behavior, 37(2), 266-278. https://doi.org/10.1007/s10508-006-9123-6

GURBUZ, B., ONCU, E., \& KARA, F. M. (2014). Leisure Boredom Scale: the Factor Structure and the Demographic Differences. Turkish Journal of Sport and Exercise, 16(2), 28-28. https://doi.org/10.15314/tjse.201428102 
Hurlock, E. B. (2000). Psikologi Perkembangan: Suatu Pendekatan Sepanjang Rentang Kehidupan. Gramedia.

Iso-Ahola, S. E., \& Weissinger, E. (1987). Leisure and Boredom. Journal of Social and Clinical Psychology, 356-364.

Kaestle, C. E., \& Allen, K. R. (2011). The role of masturbation in healthy sexual development: Perceptions of young adults. Archives of Sexual Behavior, 40(5), 983-994. https://doi.org/10.1007/s10508010-9722-0

Karia, S., de Sousa, A., Shah, N., \& Sonavane, S. (2015). Compulsive Masturbation in a Patient with Delusional Disorder. Journal of Mental Health and Human Behavior, 20(1), 38-40.

Kasemy, Z., Desouky, D. E. S., \& Abdelrasoul, G. (2016). Sexual Fantasy, Masturbation and Pornography Among Egyptians. Sexuality and Culture, 20(3), 626-638. https://doi.org/10.1007/s12119-0169346-1

Kontula, O., \& Haavio-Mannila, E. (2003). Masturbation in a generational perspective. Journal of Psychology and Human Sexuality, 14(2-3), 49-83. https://doi.org/10.1300/J056v14n02_05

Neuman, W. L. (2007). Basic of Social Research: Qualitative and Quantitative Approaches. Pearson.

Ngadiyo. (2010). How To Handle Masturbation: Tips Aman Dapatkan Kenikmatan Abadi. PT. Tiga Serangkai Pustaka Mandiri.

Noor, R. (2015). HUBUNGAN ANTARA KONTROL DIRI DENGAN PERILAKU SEKSUAL REMAJA PADA SISWA SMK ISTIQOMAH MUHAMMADIYAH 4 SAMARINDA.

Parasantya, B. W. (2019). Hubungan Perilaku Masturbasi dan Perasaan Bersalah pada Narapidana di Rumah Tahanan Kelas I Medaeng Surabaya.

Ramachandran, V. S. (2002). Encyclopedia of the Human Brain. Academic Press.

Ray, J., \& Afflerbach, S. (2014). Sex Education and Attitudes toward Masturbation. In Jannine and Afflerbach

(Vol.

14). https://cornerstone.lib.mnsu.edu/jurAvailableat:https://cornerstone.lib.mnsu.edu/jur/vol14/is s1/8

Rizaldi, G. F. (2014). Hubungan antara Frekuensi Masturbasi dengan Indeks Prestasi belajar pada Mahasiswa Fakultas Kedokteran Universitas Sebelas Maret.

Sharafi, M. R. (2000). World of Teenagers. Culture Institution of Education.

Shekarey, A., Sedaghat Rostami, M., Mazdai, K., \& Mohammadi, A. (2011). Masturbation: Prevention and treatment. Procedia - Social and Behavioral Sciences, 30, 1641-1646. https://doi.org/10.1016/j.sbspro.2011.10.318

Siswanto, S., \& Rezda, T. (2014). Hubungan Pengetahuan Tentang Masturbasi, Kontrol Diri, dan Paparan Media Pornografi Terhadap Perilaku Masturbasi Mahasiswa yang Tinggal di Asrama di Samarinda Tahun 2012.

Tukan, J. S. (1993). Metode Pendidikan Seks, Perkawinan, dan Keluarga. Erlangga. 
Warlenda, S. V., Wahyudi, A., \& Siregar, Z. S. (2018). Determinan Masturbasi pada Remaja di SMA Negeri 3 Tapung Kabupaten Kampartahun 2017. Jurnal Kesehatan Komunitas, 4(2), 46-51. https://doi.org/10.25311/keskom.vol4.iss2.257 